\title{
Optimized non-orthogonal multiplexing in Peak Power Limited Channels
}

\author{
Nader Alagha, Farbod Kayhan and Guido Montorsi*
}

\begin{abstract}
In this paper, we investigate the performance of optimized non-orthogonal modulation schemes and compare the results with orthogonal time division multiplexing assuming a peak power limited AWGN channel. We show that significant gains can be achieved by properly designing the constellation set, specially in the presence of large SNIR imbalance between the user's link quality. We introduce two realistic case studies and present the results for each scenario.
\end{abstract}

\section{Introduction}

In multi-user satellite downlink channel, orthogonal resource sharing techniques, such as time division multiplexing (TDM), are commonly used for serving multiple users within the coverage area. Even though in general, the orthogonal multiplexing schemes are known to be sub-optimal over the Additive White Gaussian Noise (AWGN) channel with average power constraint, many systems still adopt them due to their simple transmitter/receiver structure. In order to increase the throughput, one may also optimize coding and modulation scheme according to each user's link quality. Such schemes are commonly referred to as adaptive coding and modulation (ACM).

In recent years, open standards such as the DVB-S2X ${ }^{1}$ have extended the range of supported coded and modulation to cover signal to noise quality thresholds from -10 dB to $20 \mathrm{~dB}$. The high-end SNR range ensures the spectral efficiency for professional services while the very low SNR (VL-SNR) range allows the co-existence of small and mobile terminals on the carrier. The coexistence of services on the same multiplex is essential for the mobile services because market demand for VL-SNR may not be as large to justify the allocation of a full transponder to such services. ${ }^{2,3}$

Over the AWGN channel, superposition modulation is shown to be capacity achieving under average power constraint with a feasible added complexity. ${ }^{4}$ However, under the peak power constraint, no results regarding the optimality of superposition is available in the literature. ${ }^{5}$

In this paper, we investigate the performance of optimized non-orthogonal modulation schemes with peak power constraint and compare the results with both TDM (orthogonal) modulation. Our results show that by properly optimizing the non-orthogonal scheme it is possible to achieve larger throughput compared to the orthogonal one. This is particularly the case when there is a large difference between the user terminals link qualities (for example due to different receiving antenna gains). For users with poor link quality, the impact of the overlay signal in performance is negligible (slightly worse) and the receiver structure remains the same as TDM solution. For the users with higher link quality, the interference caused by overlaying signal can be removed and a higher spectral efficiency can be reached at the expense of relatively more baseband receiver complexity. Since both set of users have access to the resources at the same time there is no delay jitter or scheduling complexity at the transmitter.

Contrary to what happen with the average power constraint we show that adopting superposition modulation is not anymore optimal.

We present our results for two realistic case studies, where a large difference between the user's quality link is unavoidable.

The rest of this paper is organized as follows. In section II we present two scenarios in which having a large SNR imbalance between the user's link quality is unavoidable. In section III we briefly review some basic

${ }^{*}$ Nader Alagha is with the European Space Technology Centre, ESA/ESTEC, Keplerlaan 1, 2200 AG Noordwijk ZH (Email: nader.alagha@esa.int). Farbod Kayhan is a research associate at Interdisciplinary Centre for Security, Reliability and Trust (SnT), university of Luxembourg, L-2721, Luxembourg (Email: farbod.kayhan@uni.lu). Guido Montorsi is with politecnico di Torino, DET, 10129, Toirno, Italy (Email: guido.montorsi@polito.it) 
concepts and introduce the notations used in this paper. The signalling optimization problem is described in section IV where the mutual information is introduced as the objective function to be optimized. We present the optimization results in Section V. Finally, the paper is concluded in Section VI.

\section{Case Studies}

In this section we describe two realistic system scenarios that we will consider in this paper. The signaling optimization and the comparison with state of the art techniques are presented for these two study cases in section V.

\section{A. Case Study 1: Aeronautical and Fixed Satellite services}

In the first scenario we consider a system where a Ku-band transponder is deployed to serve two classes of users:

1. Aeronautical user terminals with a constraint on the antenna size (effective antenna size $30 \mathrm{~cm}$ )

2. Fixed satellite user terminals with 1.2 meters antenna size

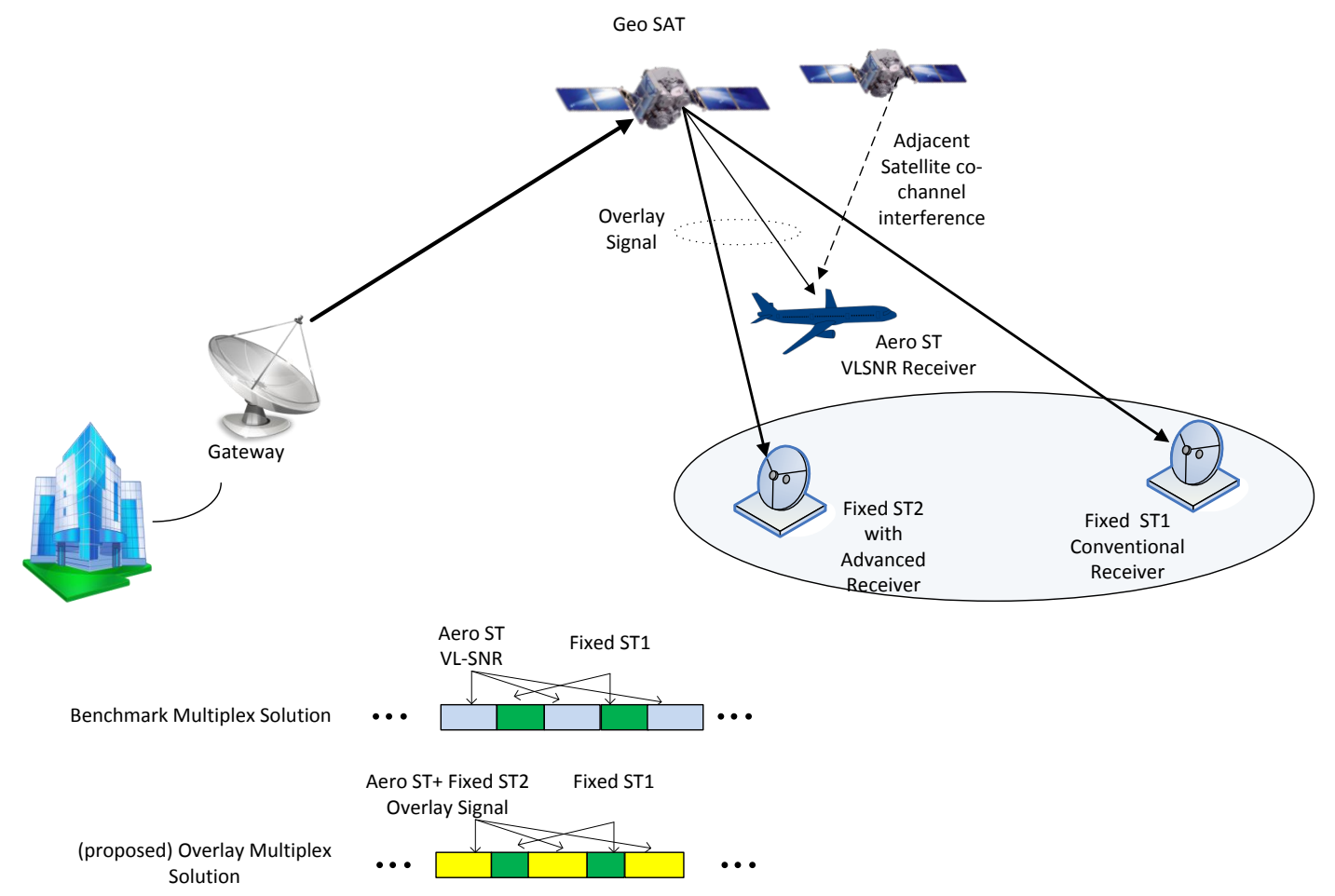

Figure 1. System scenario for the first case study.

Figure 1 illustrates this system scenario in which both aeronautical and fixed satellite services are served by the same forward link carrier. There is around $20 \log 10(1.2 / 0.3)=12 \mathrm{~dB}$ difference between the signal to noise ratio observed by the two classes of the user terminals. Furthermore, the aeronautical terminal is more susceptible to adjacent satellite interference due to less directivity of the antenna. We consider two system solutions for this case study. The first solution is based on conventional ACM and time sharing. The second solution uses similar time sharing structure as solution one but replaces the VL-SNR modulation and coding with an overlay signal that is detected by aeronautical receiver as well as the receiver with interference cancellation capability. The frame structure is also shown in Figure 1. 
It should be noted that the same Aero terminals are used for both system solutions. In the proposed overlay signal solution, a more protected modulation and coding is required (still within the range of VL-SNR solutions offered by DVB-S2X) to serve the Aero terminals due to the power split between two layers.

\section{B. Caso study 2: Continuous Aero Service}

In this case, it is assumed that all fixed terminals are capable of overlay signal detection and decoding (corresponding to ST2 in the previous case). As a result, the transponder resources can be shared between Aero terminal and the ST2 terminals all the time. Figure 2 illustrates this scenario.

In this example, the overlay signal is designed to deliver service to Aero terminal continuously (no time sharing) as the primary service. In addition, the advanced receiver with a higher link quality reception (larger antenna) can detect and remove the first layer subsequently decode the second layer.

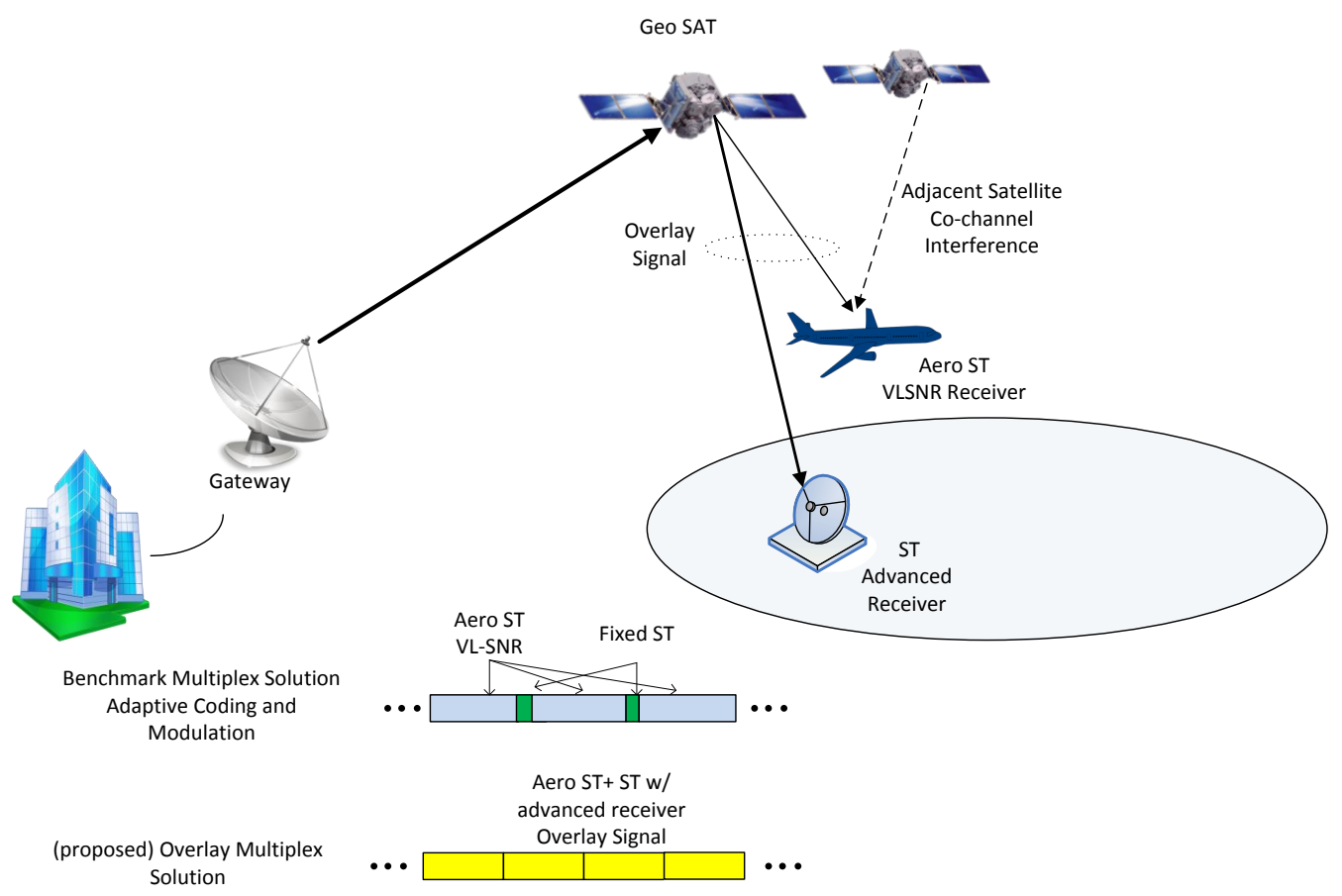

Figure 2. System scenario for the second case study.

\section{Basic concepts}

We consider two non-orthogonal multiplexing schemes in this paper. The first scheme is referred to as overlay modulation. The second scheme is referred to as "superposition modulation" and can be considered as a special case of the general overlay modulation scheme. We also describe in details the receiver structure for both schemes. ${ }^{\text {a }}$

\section{A. Overlay Modulation}

The block diagram of the general overlay modulation scheme (including the encoder and modulation blocks) is reported in Figure 3. The set of $N$ data streams are encoded by using independent powerful (turbo-like) binary codes with code rates $r_{i}$, generating the sequence of coded bits $c_{i}$ that are interleaved and sent to the mapper. We refer to each data stream as a layer in the rest of this paper. The encoded bits, independently

\footnotetext{
${ }^{a}$ In the literature, sometimes the term hierarchical modulation is used for what we call overlay modulation scheme. We discarded the use of this term in order to avoid any inconsistency with other uses of hierarchical modulation in the literature.
} 
generated for each layer, are grouped into blocks of $m_{i}$ bits and mapped to a constellation set of cardinality $M=2^{m}$ with

$$
m=\sum_{i=1}^{N} m_{i} .
$$

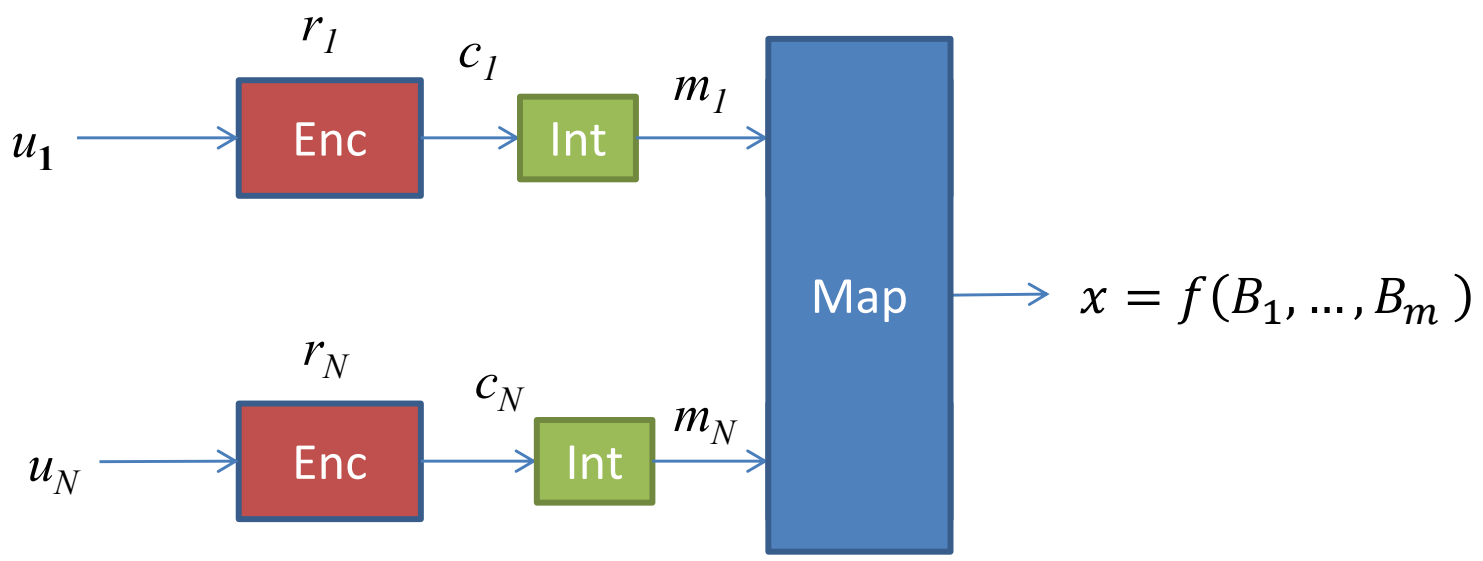

Figure 3. Block diagram of the transmitter general overlay modulation scheme. The bits generated by the encoders associated to different layers are mapped to a constellation set of cardinality $M=2^{m}$.

The design of this transmitter scheme requires the choice of the rates of binary encoders $r_{i}$, the modulation efficiencies of each layer $m_{i}$, the complex constellation set (image of $f$ ), as well as the binary labeling $f\left(B_{1}, \ldots, B_{m}\right)=f(\mathbf{B})$.

\section{B. Linear superposition of layers and Superposition Modulation (SM+SL)}

The block diagram of the second considered encoding and modulation scheme is reported in Figure 4.

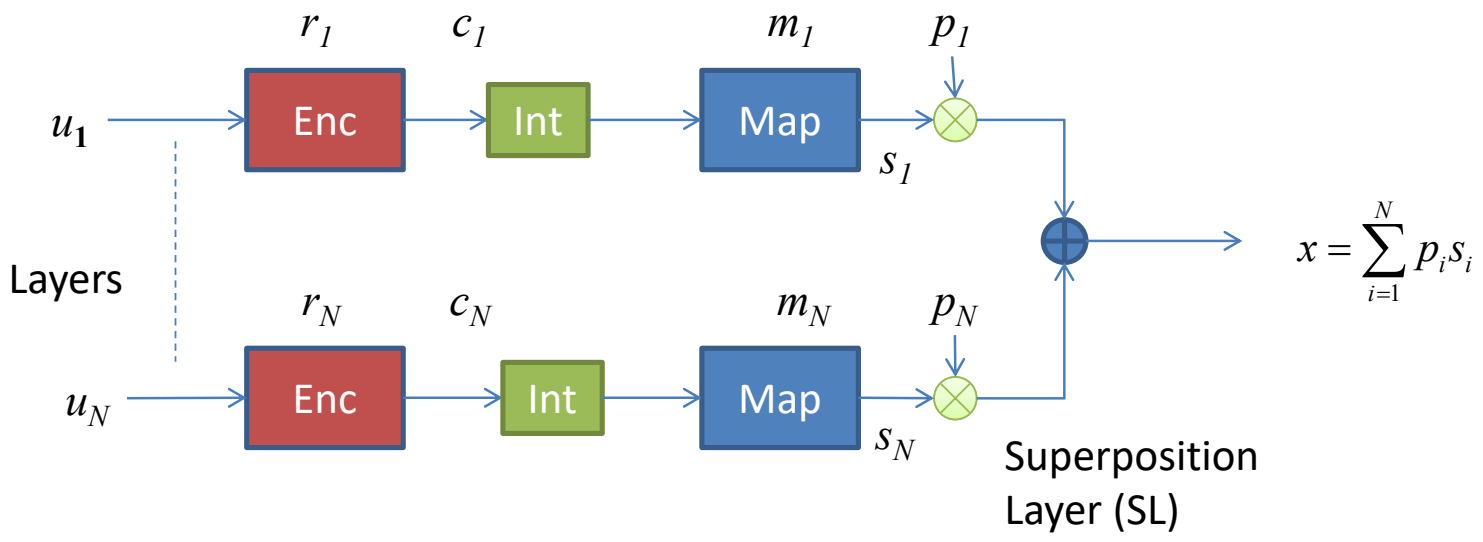

Figure 4. Block diagram of the transmitter scheme with superimposed layers (SL).

As in the previous case, the set of $N$ layers are encoded by using independent powerful (turbo-like) binary codes with code rates $r_{i}$, generating the sequence of coded bits $c_{i}$ that are interleaved and sent to the mapper. For each layer, the mapper groups blocks of $m_{i}$ bits and select a constellation point from a two-dimensional constellation with cardinality $M_{i}=2^{m_{i}}$. The spectral efficiency associated to the layer is then $R_{i}=r_{i} m_{i}$. The constellation points from different layers are then superimposed by using a set of real or complex coefficients $p_{i}$, yielding the transmitted symbol:

$$
x=\sum_{i=1}^{N} p_{i} s_{i} .
$$


Notice that the block diagram in Figure 4 is representative of any superposed layer (SL) scheme found in literature. The different proposed design solutions consider different adopted modulation sets, set of rates and performance measures for the design of the transmitter. None of the solutions proposed in literature provide a specific design method that is suited for the adoption of this technique over the non-linear channel.

Superposition Modulation (SM) has been proposed by several authors as an efficient way to build modulation sets achieving performance close to the Shannon limit. Also in this case, the modulation symbols are obtained by linearly superposing binary sequences $c_{j}$ with suitable real or complex coefficients (see Figure 5):

$$
s=\sum_{j=1}^{m} \beta_{j}\left(1-2 c_{j}\right)
$$

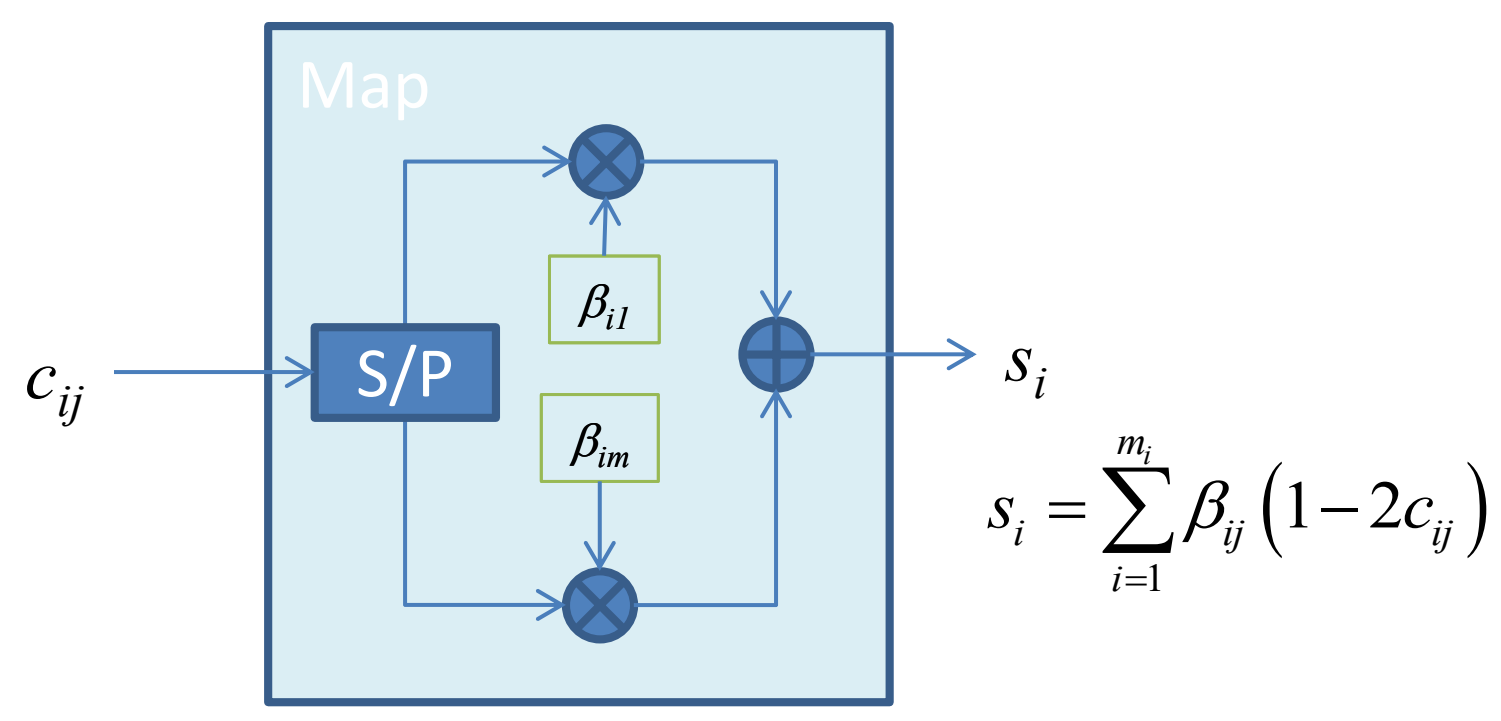

Figure 5. Block diagram of the superposition modulator (SM).

This technique indeed has been shown to yield performance close to the optimal when the coefficients $\beta_{i j}$ are properly optimized.

SM is then constructed using the same approach previously described for the superposed layers. The difference here is that bits used for constructing the modulation symbols are associated to the same layer and thus generated by the same encoder. It seems natural and efficient in the broadcast scenario to pair the SL technique with the SM technique, yielding the encoding and modulation scheme represented in Figure 6,

$$
x=\sum_{i=1}^{N} p_{i} s_{i}=\sum_{i=1}^{N} \sum_{j=1}^{m_{i}} p_{i} \beta_{i, j}\left(1-2 c_{i j}\right)=\sum_{k=1}^{m} a_{k}\left(1-2 B_{k}\right)=f_{S M}(\mathbf{B})
$$

where $c_{i j}$ is the $j^{t h}$ bit generated by the $i^{\text {th }}$ layer, while $B_{k}$ denotes a generic bit at the input of the superposition mapper. Design of this transmitter scheme requires the choice of the rates of binary encoders $r_{i}$, the modulation efficiencies of each layer $m_{i}$, and the $m$ complex coefficients $a_{k}$ that jointly define the superposition modulation and the superposition of layers (SM+SL).

\section{Receiver Structure}

A block diagram of an iterative receiver for the non-orthogonal modulation scheme is shown in Figure 7. The samples at the output of the matched filter $y$, enter the block named "detector" that computes the LogLikelihood Ratios (LLR) of the transmitted symbols $\lambda\left(s_{i}\right)$ for each layer. The symbols LLRs are converted to bit LLR by the Soft Output Mapper block (SOMAP), and the sequence of interleaved bits LLR enter the turbo decoder associated to each layer. The superposition of layers requires that iterations are performed between decoder and detector to achieve acceptable performance. For each iteration, the updated extrinsic from each decoder is fed back to the detector, which updates the LLR computation by exploiting the extrinsic information coming from other superimposed symbols. 


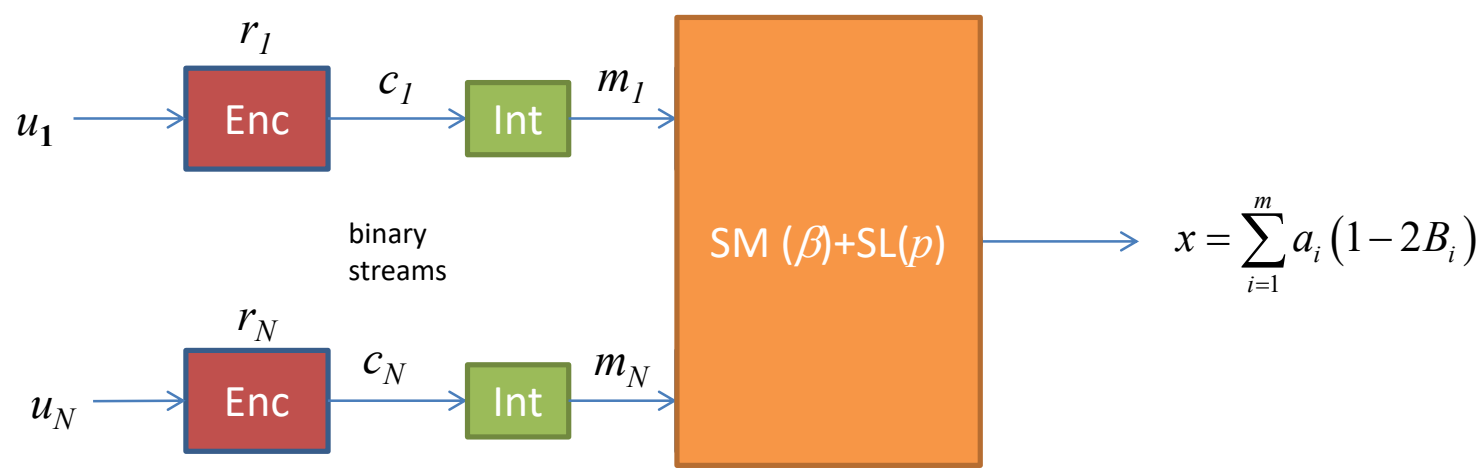

Figure 6. Block diagram of the transmitter scheme with SM+SL.

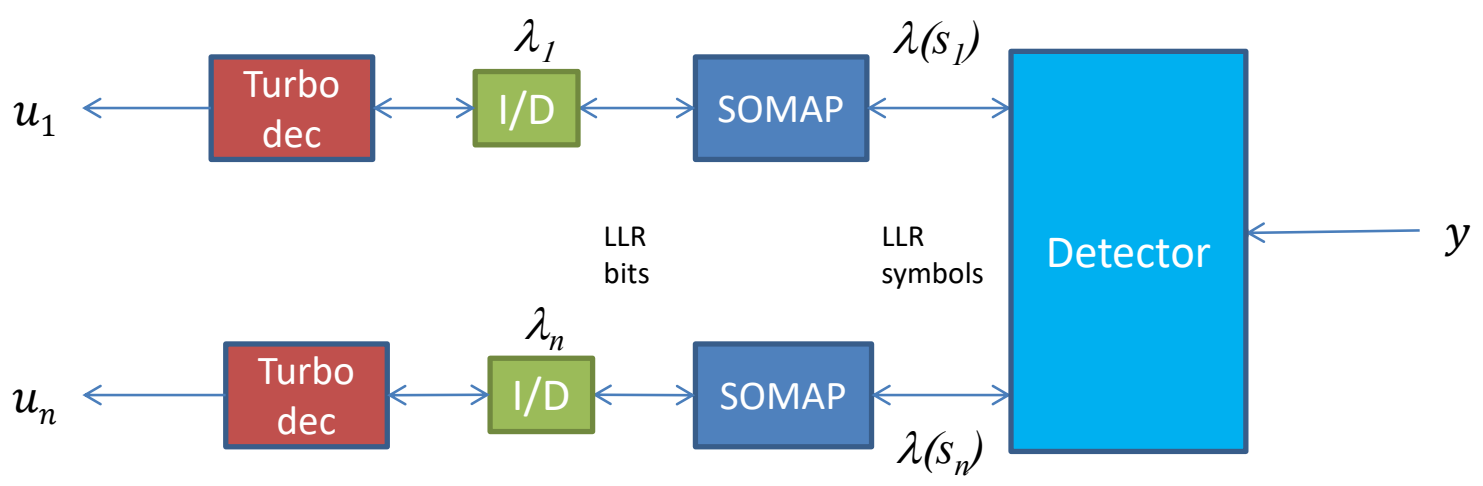

Figure 7. Block diagram of a generic receiver for the superposition scheme of Figures 3 and 6.

The detector block takes the samples at the output of the channel and the extrinsic LLR on the $m$ binary streams fed back from the $N$ decoders and computes the updated extrinsic LLR. All iterative receivers adopted for transmitter schemes like those represented in Figure 3 fall in the considered generic receiver reported in Figure 7. The difference among different implementations is due to the adopted scheduling of iterations between detector and decoders of the different layers and in the implementation of the detector block, which has a crucial impact on both the complexity and the performance of the receiver.

As an example "onion peeling" or SIC receiver starts decoding a given layer only when reliable decisions are available from the previous layer.

Furthermore, when BICM (pragmatic) approach is adopted, during the decoding of a given layer no iteration take place between detector and decoder and iterations are only performed within the (turbo) decoder.

\section{Signal space optimization}

In this section we present our methodology for signal space optimization for the overlay modulation scheme. We first review the transmitter system and then define the objective function to be optimized.

\section{A. Design of non-orthogonal transmitter systems}

Given the proposed transmitter (Figure 3 and Figure 6) and receiver (Figure 7) schemes the following is the design methodology that we have adopted.

Scenario setting: Each scenario is described by providing the number of required data streams (layers) $N$, the relative rate of each data stream through a vector $\left(1, R_{2}^{*} / R_{1}^{*}, \ldots, R_{N}^{*} / R_{1}^{*}\right)$, the relative attenuation of each user class with respect to the worst one, assumed to be the first one, through the vector $\left(\alpha_{1}^{*} / \alpha_{2}^{*}, \ldots, \alpha_{1}^{*} / \alpha_{N}^{*}\right)$, the signal to noise ratio of the worst user class $\gamma$, and the interference to noise ratio of 
the worst user $\gamma_{I}$. The signal to noise plus interference ratio of each user class can then be obtained as

$$
S N I R_{j}=\frac{\gamma}{\alpha_{j}^{*} / \alpha_{1}^{*}+\gamma_{I}} .
$$

TX type: We consider the two encoding schemes of Figure 3 and Figure 4 . The total number of bits of the modulation set $m$ is fixed.

RX type: We consider an ideal SIC receiver where each layer is decoded sequentially. Furthermore we also consider pragmatic receivers where no iterations take place on a single layer between detector and decoder.

Power constraint: Two types of power constraint were considered. Peak power constraint and average power constraint.

Given the broadcast scenario setting, the power constraint and the TX type and the adopted RX scheme (pragmatic or not pragmatic), we design the modulation set, the corresponding binary labeling and the optimal allocation vector of modulation bits to layers $\left(m_{1}, m_{2}, \ldots, m_{N}\right)$, so that the vector of average mutual information under ideal SIC decoding for each service, $\left(I_{1}, \ldots, I_{N}\right)$, satisfies

$$
\left(I_{1}, \ldots, I_{N}\right) \geq \eta\left(1, R_{2}^{*} / R_{1}^{*}, \ldots, R_{N}^{*} / R_{1}^{*}\right),
$$

with $\eta$ as large as possible. From this equation, the required code rates for the binary codes is then obtained as:

$$
\left(r_{1}, \ldots, r_{N}\right)=\left(I_{1} / m_{1}, \ldots, I_{N} / m_{N}\right)
$$

We then pick the set of the encoders within the class of LDPC encoders defined in the DVB-SX standard by choosing those with the closest but smaller rate. The resulting TX structure is reported in Figure 8 .

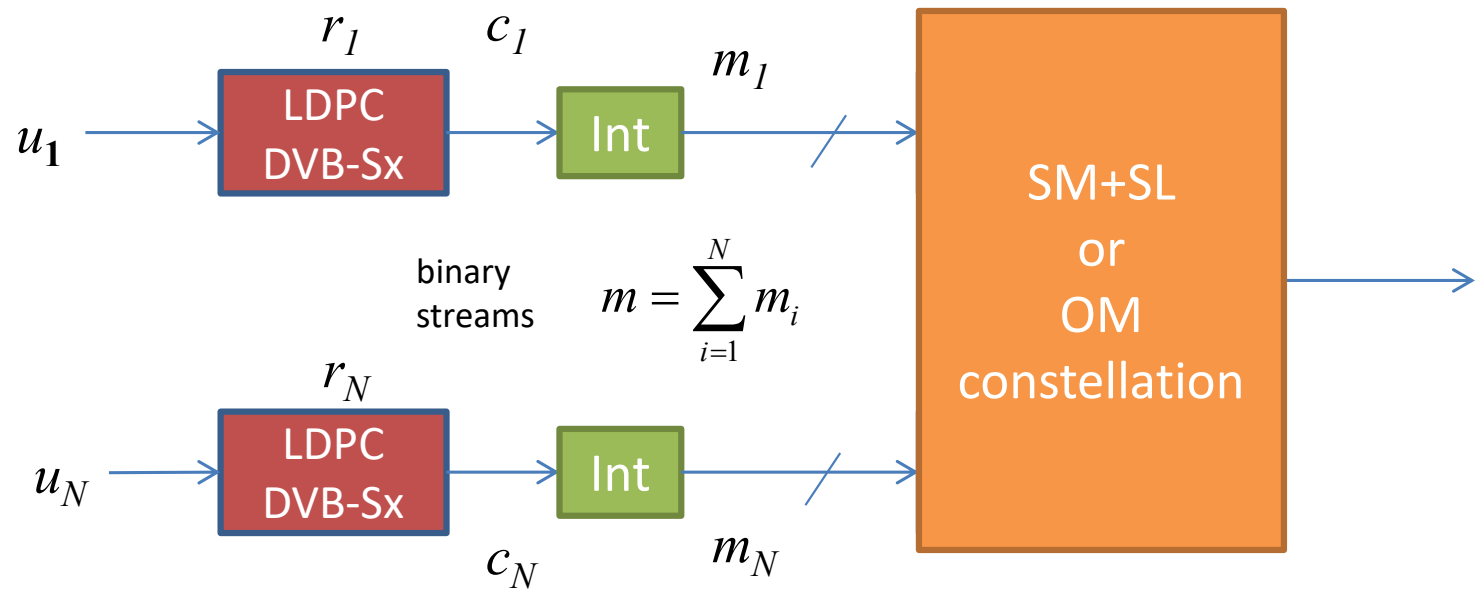

Figure 8. General structure of the designed TX system.

\section{B. Mutual Information as objective functions}

Corresponding to the optimization problem mentioned before, in this section we present the objective functions that has been maximized. We assume an ideal SIC receiver. The output of the AWGN channels relative to the $N$ layers can be written as

$$
Y_{j}=x\left(B_{1}, \ldots, B_{m}\right)+Z_{j} \quad \forall j \in[1, . ., N],
$$

The SIC receiver mutual information of the $j^{\text {th }}$ layer can be defined as

$$
I_{j}^{(S I C)}=I\left(B_{b_{j}}^{b_{j+1}-1} ; Y_{j} \mid B_{1}^{b_{j}-1}\right)
$$

where $b_{j}$ is the index of the first bit associated to the $j^{\text {th }}$ layer:

$$
b_{j}=1+\sum_{i=1}^{j-1} m_{i}
$$


and $B_{a}^{b} \triangleq\left(B_{a}, \ldots, B_{b}\right)$. As we are interested in designing a system guaranteeing a given rate vector $R^{*}=$ $\left(R_{1}^{*}, \ldots, R_{N}^{*}\right)$ rather than the sum rate, the objective function in this case is defined as:

$$
\eta^{(S I C)}(f(\mathbf{B}))=\min _{1 \leq j \leq N} \frac{1}{R_{j}^{*}} I\left(B_{b_{j}}^{b_{j+1}-1} ; Y_{j} \mid B_{1}^{b_{j}-1}\right),
$$

So that the optimized constellation will be able to reliably support the rate vector

$$
\left(I_{1}^{(S I C)}, \ldots, I_{N}^{(S I C)}\right) \geq \eta^{(S I C)}\left(R_{1}^{*}, \ldots, R_{N}^{*}\right) .
$$

When using pragmatic SIC receiver, while we still assume that previous layers have been reliably decoded, the individual $m_{i}$ bits associated to each layer are detected independently, and the correspondent pragmatic MI of each stage is then

$$
I_{j}^{(S I C, b)}=\sum_{i=b_{j}}^{b_{j+1}-1} I\left(B_{i} ; Y_{j} \mid B_{1}^{b_{j}-1}\right),
$$

and consequently the objective function becomes:

$$
\eta^{(S I C, b)}(f(\mathbf{B}))=\min _{1 \leq j \leq N} \frac{1}{R_{j}^{*}} \sum_{i=b_{j}}^{b_{j+1}-1} I\left(B_{i} ; Y_{j} \mid B_{1}^{b_{j}-1}\right),
$$

The optimized constellation will be then able to support the rate vector

$$
\left(I_{1}^{(S I C, b)}, \ldots, I_{N}^{(S I C, b)}\right) \geq \eta^{(S I C, b)}\left(R_{1}^{*}, \ldots, R_{N}^{*}\right) .
$$

\section{Simulated Annealing for constellation design}

As we have mentioned in the previous subsection, our objective function is to find the constellation and the mapping $f(\mathbf{B})$ that maximizes the mutual information vector in eq. (8) or eq. (10). This optimization problem is in general non-linear and difficult to tackle. In this paper we use the simulation annealing algorithm which is show to be quite effective for constellation design problem. ${ }^{6,7}$ We kindly refer the readers to $^{6}$ and $^{7}$ for details on how the simulated annealing can be adapted to this optimization problem.

\section{Optimization Results}

\section{A. Comparison of overlay and orthogonal approaches with optimized finite size constellations}

In tables 1 to 4 we report the comparisons of achievable throughput that can be obtained with orthogonal and non-orthogonal approaches in several scenarios for case study 2. Tables report the results for 4, 8, 16 and 32 point constellations.

Each table reports results for eight possible scenarios, according to possible configurations of the following parameters:

1. Peak or average power constraint,

2. BICM receiver (pragmatic approach) or optimal receiver in each layer,

3. Superposition modulation (SM+SL) or overlay modulation $(\mathrm{OM})$.

The columns 4 to 7 in the tables report the achievable throughput of the two data streams obtained adopting an orthogonal or non-orthogonal schemes. The design of the two approaches constrained the throughput of the first layer to be identical. The final 8-th column provides the relative throughput gain of the second layer of non-orthogonal w.r.t. orthogonal signalling. The gain is computed as

$$
\text { Gain 2nd service }=\frac{\text { Non-Orthogonal }[2]-\text { Orthogonal }[2]}{\text { Orthogonal }[2]}
$$

where "orthogonal [2]" and "non-orthogonal [2]" are respectively the throughput of the second layer in Mbps for the orthogonal and non-orthogonal schemes. 


\begin{tabular}{|c|c|c|r|r|r|r|r|}
\hline $\begin{array}{c}\text { Peak power } \\
\text { constraint? }\end{array}$ & $\begin{array}{c}\text { Pragmatic MI } \\
\text { optimization? }\end{array}$ & SM+SL/OM & $\begin{array}{c}\text { Orthogonal } \\
{[\mathbf{1}] \text { [Mbps] }}\end{array}$ & $\begin{array}{c}\text { Orthogonal } \\
\text { [2] [Mbps] }\end{array}$ & $\begin{array}{c}\text { Non } \\
\text { Orthogonal } \\
{[\text { 1] [Mbps] }}\end{array}$ & $\begin{array}{c}\text { Non } \\
\text { Orthogonal } \\
\text { [2] [Mbps] }\end{array}$ & $\begin{array}{c}\text { Gain 2nd } \\
\text { service }\end{array}$ \\
\hline NO & NO & OM & 10.9 & 20.2 & 10.9 & 24.5 & $21 \%$ \\
\hline YES & NO & OM & 10.9 & 17.9 & 10.9 & 24.5 & $37 \%$ \\
\hline NO & YES & OM & 10.9 & 20.2 & 10.9 & 24.5 & $21 \%$ \\
\hline YES & YES & OM & 10.9 & 17.9 & 10.9 & 24.5 & $37 \%$ \\
\hline NO & NO & SM+SL & 10.9 & 20.2 & 10.9 & 24.4 & $21 \%$ \\
\hline YES & NO & SM+SL & 10.9 & 17.9 & 10.9 & 24.4 & $37 \%$ \\
\hline NO & YES & SM+SL & 10.9 & 20.2 & 10.9 & 24.4 & $21 \%$ \\
\hline YES & YES & SM+SL & 10.9 & 17.9 & 10.9 & 24.5 & $37 \%$ \\
\hline
\end{tabular}

Table 1. Comparison of non-orthogonal vs orthogonal approaches for the case study 2. Modulation sets of cardinality 4. Peak and average power constraints, pragmatic and not pragmatic decoders, superposition modulation and overlay modulations

\begin{tabular}{|c|c|r|r|r|r|r|r|}
\hline $\begin{array}{c}\text { Peak power } \\
\text { constraint? }\end{array}$ & $\begin{array}{c}\text { Pragmatic MI } \\
\text { optimization? }\end{array}$ & SM+SL/OM & $\begin{array}{c}\text { Orthogonal [1] } \\
\text { [Mbps] }\end{array}$ & $\begin{array}{c}\text { Orthogonal [2] } \\
\text { [Mbps] }\end{array}$ & $\begin{array}{c}\text { Non Orthogonal } \\
\text { [1] [Mbps] }\end{array}$ & $\begin{array}{c}\text { Non Orthogonal } \\
\text { [2] [Mbps] }\end{array}$ & Gain 2nd service \\
\hline NO & NO & OM & 11.1 & 18.9 & 11.1 & 24.9 & $32 \%$ \\
\hline YES & NO & OM & 11.0 & 17.1 & 11.0 & 24.7 & $44 \%$ \\
\hline NO & YES & OM & 11.1 & 18.9 & 11.1 & 24.9 & $32 \%$ \\
\hline YES & YES & OM & 10.9 & 17.8 & 10.9 & 25.4 & $43 \%$ \\
\hline NO & NO & SM+SL & 11.1 & 18.8 & 11.1 & 24.9 & $32 \%$ \\
\hline YES & NO & SM+SL & 10.8 & 19.0 & 10.8 & 24.1 & $27 \%$ \\
\hline NO & YES & SM+SL & 11.1 & 18.9 & 11.1 & 24.8 & $32 \%$ \\
\hline YES & YES & SM+SL & 10.9 & 17.9 & 10.9 & 24.5 & $37 \%$ \\
\hline
\end{tabular}

Table 2. Comparison of non-orthogonal vs orthogonal approaches for the case study 2. Modulation sets of cardinality 8. Peak and average power constraints, pragmatic and not pragmatic decoders, superposition modulation and overlay modulations.

\section{B. First case study}

Table 5 summarizes the key system assumptions for two system solutions. Both system solutions mentioned in section II are capable of serving Aeronautical and fixed satellite terminals and the transponder resources are shared between these two services. In the conventional ACM and time sharing approach (shown also in Figure 1 as the benchmark multiplexing solution), the transponder time is equally shared between the two services. The corresponding maximum throughput for fixed and Aero services are computed as 56.9 and 7.43 Mbits/s respectively. In the proposed overlay modulation solution, for the sake of backward compatibility, the same conventional fixed and Aero services are offered to the existing population of users (no change in the receivers). In addition, a new class of fixed satellite terminals (ST2) are deployed that can decode and remove the Aero signal from an overlay signal and detect the second layer that is targeted merely for ST2 terminals. The time share between services and the power allocation are adjusted such that the Aero terminals receive the same throughput for both benchmark and overlay solutions $(\approx 7.45 \mathrm{Mbits} / \mathrm{s})$. As reported in table 1 , the overall throughput of the fixed terminals is increased to $51.2+16.7=67.9 \mathrm{Mbits} / \mathrm{s}$ that is around $20 \%$ increase in the throughput for the fixed terminals while maintaining the same throughput for Aero terminals. In addition, the existing fixed terminals can still be served by the TDM (with a slightly lower throughput).

\section{Second case study}

Table 6 summarizes the key system assumptions for two system solutions; Considering $90 \%$ of the transponders power being allocated to the Aero services in overlay signal, the aggregate throughput of the Aero services reaches $13.6 \mathrm{Mbits} / \mathrm{s}$. In addition, the $10 \%$ of the transponders power is used to deliver $30.4 \mathrm{Mbits} / \mathrm{s}$ throughputs to high gain terminals.

For comparison, Table 6 also includes the same analysis for ACM (with time sharing) solution. It is shown that for the same Aero service throughput of $13.6 \mathrm{Mbits} / \mathrm{s}$, the ACM solution can only deliver $9.7 \mathrm{Mbits} / \mathrm{s}$ of 


\begin{tabular}{|c|c|c|c|c|c|c|c|}
\hline $\begin{array}{l}\text { Peak power } \\
\text { constraint? }\end{array}$ & $\begin{array}{l}\text { Pragmatic MI } \\
\text { optimization? }\end{array}$ & $\mathrm{SM}+\mathrm{SL} / \mathrm{OM}$ & $\begin{array}{l}\text { Orthogonal [1] } \\
\text { [Mbps] }\end{array}$ & $\begin{array}{c}\text { Orthogonal [2] } \\
\text { [Mbps] }\end{array}$ & $\begin{array}{c}\text { Non Orthogonal } \\
\text { [1] [Mbps] }\end{array}$ & $\begin{array}{c}\text { Non Orthogonal } \\
\text { [2] [Mbps] }\end{array}$ & Gain 2nd service \\
\hline $\mathrm{NO}$ & $\mathrm{NO}$ & OM & 11.1 & 18.7 & 11.1 & 24.8 & $33 \%$ \\
\hline YES & NO & OM & 11.0 & 17.1 & 11.0 & 24.7 & $44 \%$ \\
\hline NO & YES & OM & 11.0 & 19.3 & 11.0 & 26.2 & $36 \%$ \\
\hline YES & YES & OM & 10.9 & 17.8 & 10.9 & 25.3 & $42 \%$ \\
\hline NO & $\mathrm{NO}$ & $\mathrm{SM}+\mathrm{SL}$ & 11.1 & 18.7 & 11.1 & 24.8 & $33 \%$ \\
\hline YES & NO & $\mathrm{SM}+\mathrm{SL}$ & 10.8 & 18.8 & 10.8 & 24.6 & $31 \%$ \\
\hline NO & YES & $\mathrm{SM}+\mathrm{SL}$ & 11.1 & 19.1 & 11.1 & 25.3 & $33 \%$ \\
\hline YES & YES & $\mathrm{SM}+\mathrm{SL}$ & 10.9 & 17.9 & 10.9 & 24.4 & $36 \%$ \\
\hline
\end{tabular}

Table 3. Comparison of non-orthogonal vs orthogonal approaches for the case study 2. Modulation sets of cardinality 16. Peak and average power constraints, pragmatic and not pragmatic decoders, superposition modulation and overlay modulations.

\begin{tabular}{|c|c|c|r|r|r|r|r|}
\hline $\begin{array}{c}\text { Peak power } \\
\text { constraint? }\end{array}$ & $\begin{array}{c}\text { Pragmatic MI } \\
\text { optimization? }\end{array}$ & SM+SL/OM & $\begin{array}{c}\text { Orthogonal [1] } \\
\text { [Mbps] }\end{array}$ & $\begin{array}{c}\text { Orthogonal [2] } \\
\text { [Mbps] }\end{array}$ & $\begin{array}{c}\text { Non } \\
\text { Orthogonal [1] } \\
\text { [Mbps] }\end{array}$ & $\begin{array}{c}\text { Non } \\
\text { Orthogonal [2] } \\
\text { [Mbps] }\end{array}$ & $\begin{array}{c}\text { Gain 2nd } \\
\text { service }\end{array}$ \\
\hline NO & NO & OM & 11.9 & 12.3 & 11.9 & 26.8 & $117 \%$ \\
\hline YES & NO & OM & 11.2 & 15.9 & 11.2 & 25.3 & $60 \%$ \\
\hline NO & YES & OM & 10.8 & 21.4 & 10.8 & 42.2 & $97 \%$ \\
\hline YES & YES & OM & 10.4 & 21.3 & 10.4 & 27.3 & $28 \%$ \\
\hline NO & NO & SM+SL & 12.1 & 10.6 & 12.1 & 27.1 & $155 \%$ \\
\hline YES & NO & SM+SL & 10.7 & 19.7 & 10.7 & 24.7 & $25 \%$ \\
\hline NO & YES & SM+SL & 12.1 & 11.1 & 12.1 & 27.9 & $152 \%$ \\
\hline YES & YES & SM+SL & 10.8 & 19.1 & 10.8 & 24.3 & $27 \%$ \\
\hline
\end{tabular}

Table 4. Comparison of non-orthogonal vs orthogonal approaches for the case study 2. Modulation sets of cardinality 32. Peak and average power constraints, pragmatic and not pragmatic decoders, superposition modulation and overlay modulations.

fixed satellite service by utilizing $8.5 \%$ of the time sharing multiplex. This example shows that theoretically the signal overlay solution can deliver 30.4/9.7=3.1 times higher throughput to high gain terminals compared to that of conventional time sharing solutions.

It is also important to note that compared to ACM with time sharing, the signal overlay transmission scheme does not introduce time jitter in bit delivery to user terminals since both high gain and low gain terminals contentiously receiving useful data stream in all frames.

\section{Conclusions}

In this paper, we compared the performance of optimized overlay modulation scheme with that of time division multiplexing and superposition modulation over the peak power limited AWGN channel. We optimized the overlay modulation scheme by maximizing the mutual information of the constellation space. We showed that in the presence of large SNR imbalance between user's link, significant gains with respect to time sharing and superposition modulation can be obtained by carefully designing the overlay modulation scheme. We have also introduced two case studies where such a large imbalance between the user's ling is an intrinsic property of the channel and hence unavoidable. Gains up to $150 \%$ have been observed for such system scenarios.

\section{Acknowledgments}

This work is funded by the European Space Agency, ESA-ESTEC, Noordwijk, The Netherlands, under contract no. 4000109715. Opinions, interpretations, recommendations and conclusions expressed herein are those of the authors and are not necessarily endorsed by the European Space Agency. 


\begin{tabular}{|c|c|c|c|c|c|}
\hline No. & Parameter & Unit & $\begin{array}{l}\text { ACM+Time } \\
\text { Sharing }\end{array}$ & $\begin{array}{l}\text { Signal } \\
\text { Overlay + } \\
\text { Time } \\
\text { Sharing }\end{array}$ & Comment \\
\hline 1 & $\begin{array}{c}\text { Transponder } \\
\text { Bandwidth }\end{array}$ & $\mathrm{MHz}$ & 36 & 36 & A Ku-band transponder is considered \\
\hline 2 & $\begin{array}{l}\text { Typical Link Quality } \\
\text { for fixed satellite } \\
\text { services (C/ N+I) }\end{array}$ & $\mathrm{dB}$ & 9 & 9 & $\begin{array}{l}\text { The Link quality for fixed user terminal } \\
\text { corresponds to } 1.2 \mathrm{~m} \text { dish size (G/T } 21 \\
\mathrm{~dB} / \mathrm{K} \text { ) and satellite EIRP of } 41 \mathrm{dBW} \text { per } \\
\text { transponder. The transponder bandwidth } \\
\text { of } 36 \mathrm{MHz} \text { is considered. } \\
\text { Note that for fixed satellite terminals the } \\
\text { co-channel interference due to the adjacent } \\
\text { satellites is considered negligible. }\end{array}$ \\
\hline 3 & $\begin{array}{l}\text { Average percentage } \\
\text { of time serving fixed } \\
\text { user terminals } \\
\text { (conventional } \\
\text { receivers) } \\
\end{array}$ & $\%$ & 50 & 45 & $\begin{array}{l}\text { For both system solutions, a high } \\
\text { percentage of the time multiplex is } \\
\text { reserved for fixed satellite terminals. }\end{array}$ \\
\hline 4 & $\begin{array}{l}\text { Power allocation to } \\
\text { Aero service for } \\
\text { overlay signal }\end{array}$ & $\%$ & - & 90 & $\begin{array}{l}\text { The overlay signal consists of two terms } \\
\text { one decodable by Aero terminals with } 90 \% \\
\text { of the signal power. The remaining power } \\
\text { (10\%) is used for the second layer that is } \\
\text { only detectable and decodable by advanced } \\
\text { fixed receivers. }\end{array}$ \\
\hline 5 & $\begin{array}{l}\text { SNR for Aero } \\
\text { Terminal }\end{array}$ & $\mathrm{dB}$ & -3 & -3.5 & $\begin{array}{l}12 \mathrm{~dB} \text { lower SNR compared to that of fixed } \\
\text { satellite terminal. } \\
\text { The C/N reduction of the overlay signal is } \\
\text { due to power split between two signal } \\
\text { layers. }\end{array}$ \\
\hline 6 & $\begin{array}{l}\text { Signal to } \\
\text { Interference ratio } \\
\text { (C/I) for Aero } \\
\text { Terminal }\end{array}$ & $\mathrm{dB}$ & 0 & 0 & $\begin{array}{l}\text { Due to the small size of the antenna, the } \\
\text { adjacent satellite co-channel interference } \\
\text { is present. The antenna has a wide beam } \\
\text { and two adjacent satellites contribute to } \\
\text { c0-channel interference. }\end{array}$ \\
\hline 7 & $\begin{array}{l}\text { Total } \mathrm{C}(\mathrm{N}+\mathrm{I}) \text { for } \\
\text { Aero Terminal }\end{array}$ & $\mathrm{dB}$ & -4.8 & -5.25 & $\begin{array}{l}\text { Taking into account both } \mathrm{C} / \mathrm{N} \text { and } \mathrm{C} / \mathrm{I} \text { as } \\
\text { shown in previous lines. }\end{array}$ \\
\hline 8 & $\begin{array}{l}\text { Theoretical } \\
\text { aggregate fixed } \\
\text { user terminal } \\
\text { throughput }\end{array}$ & Mbits/s & 56.9 & 51.2 & $\begin{array}{l}\text { Theoretical capacity as a function of total } \\
\text { bandwidth and SNIR. Considering the } \\
\text { percentage of time allocated to the service. }\end{array}$ \\
\hline 9 & $\begin{array}{l}\text { Theoretical } \\
\text { aggregate Aero } \\
\text { terminal } \\
\text { throughput }\end{array}$ & Mbits/s & 7.43 & 7.46 & $\begin{array}{l}\text { Both solutions offer the same throughput } \\
\text { to Aero terminals }\end{array}$ \\
\hline 10 & $\begin{array}{l}\text { Theoretical } \\
\text { throughput of } \\
\text { advanced fixed } \\
\text { receivers }\end{array}$ & Mbits/s & - & 16.7 & $\begin{array}{l}\text { Additional capacity that is only achievable } \\
\text { using signal overlay technique }\end{array}$ \\
\hline
\end{tabular}

Table 5. First case study: key system assumptions. 


\begin{tabular}{|c|c|c|c|c|c|}
\hline No. & Parameter & Unit & $\begin{array}{l}\text { ACM } \\
\text { (Benchmark) }\end{array}$ & $\begin{array}{l}\text { Signal } \\
\text { Overlay }\end{array}$ & Comment \\
\hline 1 & $\begin{array}{l}\text { Transponder } \\
\text { Bandwidth }\end{array}$ & $\mathrm{MHz}$ & 36 & 36 & A Ku-band transponder is considered \\
\hline 2 & $\begin{array}{c}\text { Typical Link } \\
\text { Quality for fixed } \\
\text { satellite services } \\
(\mathrm{C} / \mathrm{N}+\mathrm{I})\end{array}$ & $\mathrm{dB}$ & 9 & 9 & $\begin{array}{l}\text { The Link quality for fixed user terminal } \\
\text { corresponds to } 1.2 \mathrm{~m} \text { dish size }(\mathrm{G} / \mathrm{T} \sim 21 \\
\mathrm{dB} / \mathrm{K}) \text { and satellite EIRP of } 41 \mathrm{dBW} \text { per } \\
\text { transponder. The transponder bandwidth } \\
\text { of } 36 \mathrm{MHz} \text { is considered. } \\
\\
\text { Note that for fixed satellite terminals the } \\
\text { co-channel interference due to the } \\
\text { adjacent satellites is considered negligible. }\end{array}$ \\
\hline 3 & $\begin{array}{l}\text { Average percentage } \\
\text { of time serving } \\
\text { fixed user terminals } \\
\text { (conventional } \\
\text { receivers) }\end{array}$ & $\%$ & 8.5 & o & $\begin{array}{l}\text { For both system solutions, a high } \\
\text { percentage of the time multiplex is } \\
\text { reserved for fixed satellite terminals. }\end{array}$ \\
\hline 4 & $\begin{array}{l}\text { Power allocation to } \\
\text { Aero service for } \\
\text { overlay signal }\end{array}$ & $\%$ & - & 90 & $\begin{array}{l}\text { The overlay signal consists of two terms } \\
\text { one decodable by Aero terminals with } 90 \% \\
\text { of the signal power. The remaining power } \\
\text { (10\%) is used for the second layer that is } \\
\text { only detectable and decodable by } \\
\text { advanced fixed receivers. }\end{array}$ \\
\hline 5 & $\begin{array}{l}\text { SNR for Aero } \\
\text { Terminal }\end{array}$ & $\mathrm{dB}$ & -3 & -3.5 & $\begin{array}{l}12 \mathrm{~dB} \text { lower SNR compared to that of fixed } \\
\text { satellite terminal. } \\
\text { The } \mathrm{C} / \mathrm{N} \text { reduction of the overlay signal is } \\
\text { due to power split between two signal } \\
\text { layers. }\end{array}$ \\
\hline 6 & $\begin{array}{l}\text { Signal to } \\
\text { Interference ratio } \\
\text { (C/I) for Aero } \\
\text { Terminal }\end{array}$ & $\mathrm{dB}$ & o & o & $\begin{array}{l}\text { Due to the small size of the antenna, the } \\
\text { adjacent satellite co-channel interference } \\
\text { is present. The antenna has a wide beam } \\
\text { and two adjacent satellites contribute to } \\
\text { co-channel interference. }\end{array}$ \\
\hline 7 & $\begin{array}{l}\text { Total } \mathrm{C}(\mathrm{N}+\mathrm{I}) \text { for } \\
\text { Aero Terminal }\end{array}$ & $\mathrm{dB}$ & -4.8 & -5.25 & $\begin{array}{l}\text { Taking into account both } \mathrm{C} / \mathrm{N} \text { and } \mathrm{C} / \mathrm{I} \text { as } \\
\text { shown in previous lines. }\end{array}$ \\
\hline 8 & $\begin{array}{l}\text { Theoretical } \\
\text { aggregate fixed } \\
\text { user terminal } \\
\text { throughput }\end{array}$ & Mbits/s & 9.7 & o & $\begin{array}{l}\text { Theoretical capacity as a function of total } \\
\text { bandwidth and SNIR. Considering the } \\
\text { percentage of time allocated to the service. }\end{array}$ \\
\hline 9 & $\begin{array}{l}\text { Theoretical } \\
\text { aggregate Aero } \\
\text { terminal } \\
\text { throughput }\end{array}$ & Mbits/s & 13.6 & 13.6 & $\begin{array}{l}\text { Both solutions offer the same throughput } \\
\text { to Aero terminals }\end{array}$ \\
\hline 10 & $\begin{array}{l}\text { Theoretical } \\
\text { throughput of } \\
\text { advanced fixed } \\
\text { receivers }\end{array}$ & Mbits/s & o & 30.4 & $\begin{array}{l}\text { Additional capacity that is only achievable } \\
\text { using signal overlay technique }\end{array}$ \\
\hline
\end{tabular}

Table 6. Second case study: key system assumptions. 


\section{References}

${ }^{1}$ ETSI 302-307-2, "Digital Video Broadcasting (DVB) Part II: DVBS2-Extensions (DVB-S2X)," 2014.

${ }^{2}$ Nader S. Alagha and Pantelis-Daniel Arapoglou, "Technology Trends for Ka-Band Broadcasting Satellite Systems," Springer International Publishing, Wireless and Satellite Systems, Volume 154, pp 147-159, 2015.

${ }^{3}$ L. Lee, M. Eroz and N. Becker, "Modulation, coding, and synchronization for mobile and very small satellite terminals, as part of the updated DVB-S2 standard," Int. J. Satell. Commun. Network, 2015, http://dx.doi.org/10.1002/sat.1132.

${ }^{4}$ T. M. Cover, "Broadcast channels," IEEE Trans. Inf. Theory, vol. 18, no. 1, pp. 214, Jan. 1972.

${ }^{5}$ H. Meric, J. Lacan, F. Arnal, G. Lesthievent and M.-L. Boucheret, "Combining Adaptive Coding and Modulation With Hierarchical Modulation in Satcom System," IEEE Transactions on Broadcasting, vol. 59, no. 4, pp. 627-637,Dec. 2013.

${ }^{6}$ F. Kayhan and G. Montorsi, "Constellation design for memoryless phase noise channels," IEEE Transactions on Wireless Communications, vol.13, no.5, pp.2874,2883, May 2014.

${ }^{7}$ F. Kayhan and G. Montorsi, "Constellation design for transmission over non-linear satellite channels," in Proc. IEEE Glob. Telecommun. Conf., Annaheim, USA, 2012. 